\title{
Delivery system for mefenamic acid based on the nanocarrier layered double hydroxide: Physicochemical characterization and evaluation of anti-inflammatory and antinociceptive potential
}

\author{
Vanessa R.R. Cunha ${ }^{\mathrm{a}}$, Viviane A. Guilherme ${ }^{\mathrm{b}}$, Eneida de Paula ${ }^{\mathrm{b}}$, Daniele R. de Araujo ${ }^{\mathrm{b}, \mathrm{c}}$, Renan O. Silva ${ }^{\mathrm{d}}$, \\ Jand V.R. Medeiros ${ }^{\mathrm{d}}$, José R.S.A. Leite ${ }^{\mathrm{d}}$, Philippe A.D. Petersen ${ }^{\mathrm{e}}$, Marianna Foldvari ${ }^{\mathrm{f}}$, \\ Helena M. Petrilli ${ }^{\text {e }}$, Vera R.L. Constantino ${ }^{\mathrm{a}, *}$ \\ a Departamento de Química Fundamental, Instituto de Química, Universidade de São Paulo, USP, Av. Prof. Lineu Prestes 748, 05508-000 São Paulo, São Paulo, Brazil \\ b Departamento de Bioquímica, Instituto de Biologia, Universidade Estadual de Campinas, 13083-970, Campinas, São Paulo, Brazil \\ c Centro de Ciências Naturais e Humanas, Universidade Federal do ABC, 09210-170 Santo André, São Paulo, Brazil \\ d Núcleo de Pesquisa em Biodiversidade e Biotecnologia, BIOTEC, Campus de Parnaíba, Universidade Federal do Piauí, UFPI, 64202020 Parnaíba, Piauí, Brazil \\ e Departamento de Física dos Materiais e Mecânica, Instituto de Física, Universidade de São Paulo, USP, 05315-970 São Paulo, São Paulo, Brazil \\ ${ }^{f}$ School of Pharmacy, University of Waterloo, N2L 3G1 Waterloo, Ontario, Canada
}

\section{A R T I C L E I N F O}

\section{Article history:}

Received 7 June 2015

Received in revised form 7 August 2015

Accepted 21 August 2015

Available online 1 September 2015

\section{Keywords:}

Layered double hydroxide

Mefenamic acid

Density functional theory

Anti-inflammatory

Antinociceptive

\begin{abstract}
A B S T R A C T
Purpose: The anionic form of the drug mefenamic acid intercalated into the nanocarrier layered double hydroxide (LDH-Mef) was evaluated by anti-inflammatory and antinociceptive assays.

Methods: The LDH-Mef material was characterized by a set of physicochemical techniques, which was supported by Density Functional Theory calculations. The pharmacological effects of LDH-Mef ( $40 \mathrm{wt} \%$ of drug) were evaluated by hemolytic, anti-inflammatory activity and antinociceptive assays.

Results: In vivo assays were conducted for the first time in order to assess the LDH-Mef potential. The hemolytic effects decreased for the intercalated Mef as demonstrated by the higher tolerated hemolytic concentration $(1.83 \mathrm{mM})$ compared to mefenamic acid (MefH), $0.48 \mathrm{mM}$. Pretreatment of animals with MefH or LDH-Mef reduced carrageenan-, dextran sulfate- and $\mathrm{PGE}_{2}$-induced paw edema. MefH or LDH-Mef also decrease total leucocytes and neutrophil counts of the peritoneal cavity after inflammation induction with carrageenan. In the nociception model, oral pretreatment with LDH-Mef reduced mechanical hypernociception carrageenaninduced after 3-4 $\mathrm{h}$ and also the number of writhings induced by acetic acid.

Conclusions: This work shows the increase of the anti-inflammatory and antinociceptive potential of the drug confined into the LDH, as well as, its hemolytic effect.
\end{abstract}

(C) 2015 Elsevier B.V. All rights reserved.
Abbreviations: LDH-Mef, Layered double hydroxide containing the anionic form (mefenamate anion) of the drug mefenamic acid; LDH, Layered double hydroxide MefH, Mefenamic acid; Mef, Mefenamate anion; $\mathrm{PGE}_{2}$, Prostaglandin E2; $\mathrm{M}^{\mathrm{II}}$ and $\mathrm{M}^{\mathrm{III}}$, Divalent and trivalent cations; $\mathrm{A}^{\mathrm{n}-}$, An exchangeable anion; Carcinoma A549 and normal L-132, Lung epithelial cells; HeLa, Adenocarcinoma of the cervix; HOS, Osteosarcoma; NSAIDs, Non-steroidal anti-inflammatory drugs; PXRD, Powder X-ray diffraction; CHN, Elemental chemical analyses of C, H, and N; TGA-DTG, Thermal analysis; FT-IR, Fourier transform infrared spectroscopy; FT-Raman, Fourier transform Raman spectroscopy; NaMef, Sodium mefenamate salt; DFT, Density functional theory; $\mathrm{LDH}-\mathrm{Cl}, \mathrm{Mg}, \mathrm{Al}-\mathrm{LDH}$ material containing chloride anions; TGA-DSC, Thermogravimetric analysis and differential scanning calorimetry; IR, Infrared spectroscopy; Raman, Raman spectroscopy; PBS, Phosphate buffered saline; HTAB, Hexadecyltrimethylammonium bromide; MPO, Myeloperoxidase; Sal, Saline; SEM, Standard error of the mean; ANOVA, Analysis of variance; FTIC, Fluorescein 5'-isothiocyanate dye; Conset, Concentrations for the onset of hemolysis; PGF $_{2 \alpha}$, Prostaglandin $\mathrm{F}_{2 \alpha}$

* Corresponding author.

\section{Introduction}

The entrapment of drugs into layered inorganic nanoparticles can provide sustained release minimizing the usual side effects [1]. In addition, the inorganic framework can protect bioactive molecules against degradation processes promoted by light, heat, molecular oxygen etc. and extend their shelf life. Layered double hydroxides (LDHs), also known as hydrotalcite like-compounds, are potential candidates to carry pharmaceutical substances, $[2,3,4]$ since one LDH composition in particular (specifically $\left[\mathrm{Mg}_{6} \mathrm{Al}_{2}(\mathrm{OH})_{16}\right] \mathrm{CO}_{3} \cdot 4 \mathrm{H}_{2} \mathrm{O}$ ) is already commercialized as the antacid Talcid ${ }^{\mathrm{TM}}$ and also used as excipient [5]. In the 1990s several works have shown the efficacy of Talcid in comparison with some already established antacids like for example Omeprazol [6,7]. So, the low toxicity of LDH after oral administration is well established.

LDHs present positively charged sheets (or layers) in their structures as shown in Fig. 1, A [8]. To maintain the material's electroneutrality it 

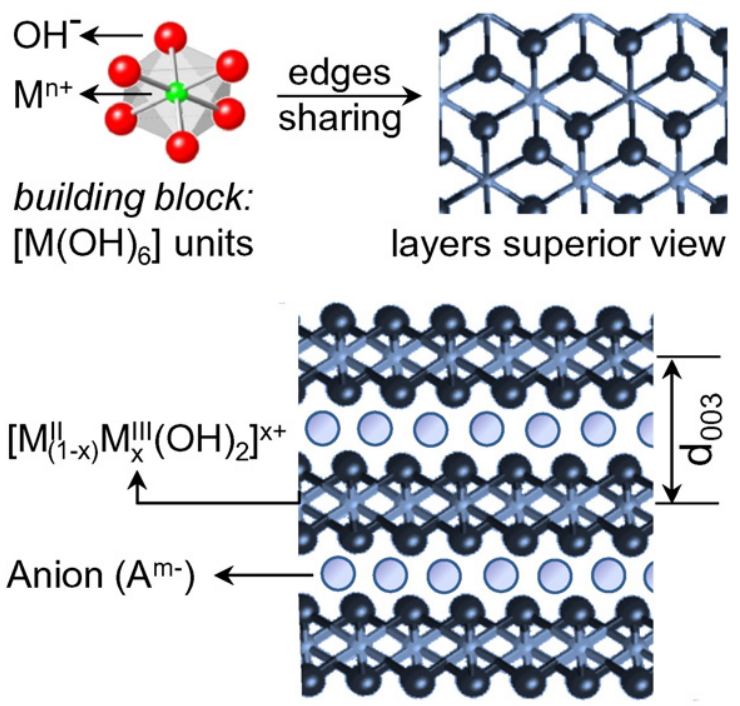

layers stacking view

(A)

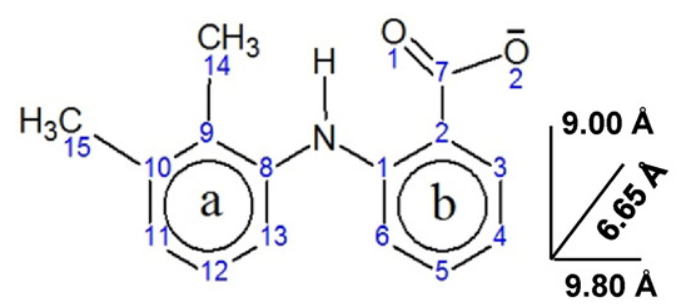

(B)

Fig. 1. Schematic representation of (A) layered double hydroxide structure, and (B) mefenamate ion structure (dimensions achieved by DFT calculations).

required the presence of anions that, together with water molecules, promote the LDHs layers stacking. The general chemical formula of this class of inorganic materials is $\left[\mathrm{M}^{\mathrm{II}}{ }_{1}-{ }_{\mathrm{x}} \mathrm{M}^{\mathrm{III}}{ }_{\mathrm{x}}(\mathrm{OH})_{2}\right]^{\mathrm{x}+}\left[\mathrm{A}^{\mathrm{n}-}\right]_{\mathrm{x} / \mathrm{n}} \cdot \mathrm{mH}_{2} \mathrm{O}$, where $\mathrm{M}^{\mathrm{II}}$ and $\mathrm{M}^{\mathrm{III}}$ are divalent and trivalent cations, and $\mathrm{A}^{\mathrm{n}-}$ is an exchangeable anion.

In the pharmaceutical and medical context, LDH is a very interesting matrix to be explored as a drug nanocarrier since it is biocompatible and the anionic form of bioactive drugs can be intercalated between its layers $[1,9]$. Therefore, since the first publication in 2001 by O'Hare group about the intercalation of commercial drugs into LDHs, [10] a growing interest in this layered material for nanotechnological purposes is noticed $[1,11,12,13,14]$.

In vitro and in vivo assays have been conducted to evaluate the LDHs' mechanisms of action when administered by enteral (oral), [15] topical, [16] or parenteral (injection) routes [17,18]. For the wide application of LDHs in the pharmaceutical and medical fields, it required the enlightenment of the cytotoxicity of these materials to provide not only information about biological applications, but also to prevent undesirable effects [19]. Choy et al. [20] have shown that these nanoparticles presented low cytotoxicity through tests in vitro with cells. The nonsteroidal anti-inflammatory drugs (NSAIDs) are suitable candidates for intercalation into LDHs due to the presence of anionic groups in their structure. Moreover, the NSAIDs present limited solubility, low bioavailability and serious gastrointestinal problems [21,22]. A recent review published by Rives et al. [23] reporting studies about anti-inflammatory drugs intercalated into LDHs has pointed out the sustained release of NSAID drugs by in vitro assays and also their pharmacological activity by in vivo tests.
Mefenamic acid (MefH, Fig. 1B), an NSAID marketed in the US as Ponstel, is indicated for inflammatory diseases and also as an analgesic for the treatment of rheumatoid arthritis, menstrual symptoms and headaches. However, due to its low solubility and side effects, mainly related to gastrointestinal adverse consequences, including bleeding, ulceration or perforation of the stomach or intestines, which can be sometimes fatal, the use of mefenamic acid is compromised [24]. Rives et al. $[25,26]$ have reported the intercalation of mefenamic acid into $\mathrm{LDH}$ and studied the release profile in different $\mathrm{pH}$ values. The release profile is slower and sustained for the intercalated mefenamate into LDH when compared to the free drug or the physical mixture containing the drug and LDH.

In this paper, we have developed LDH carriers containing magnesium and aluminum in the layers ( $\mathrm{Mg}, \mathrm{Al}-\mathrm{LDH})$ and the anionic form of mefenamic acid (LDH-Mef). LDH-Mef nanoparticles were characterized in detail by chemical analysis, powder X-ray diffraction (PXRD), thermal analysis (TGA-DTG), vibrational spectroscopy (FT-IR and FT-Raman), and particle size and zeta potential measurements. To support the experimental vibrational assignments and discuss the spectral differences between the intercalated mefenamate anion and the free anion, the calculations of vibrational frequencies of sodium mefenamate salt (NaMef) were performed in the framework of the Density Functional Theory (DFT).

In order to assess the cytotoxic effects, hemolytic assays were performed with MefH, LDH-Mef and LDH matrix without drug (i.e., $\mathrm{Mg}, \mathrm{Al}-\mathrm{LDH}$ intercalated with chloride anions). We report here the first studies on the anti-inflammatory and antinociceptive activity on systemically administered LDH-Mef nanoparticles by in vivo assays in three different inflammatory disease models, i.e. carrageenan, dextran sulfate and $\mathrm{PGE}_{2}$ induced paw inflammation models, and orally administered LDH-Mef nanoparticles in acetic acid-induced writhings model.

\section{Experimental}

\subsection{Reagents}

All reagents used in this work can be found in the Supplementary Material.

\subsection{Synthesis of LDH-Mef hybrid material}

The inorganic carrier with the drug (LDH-Mef) was isolated in order to evaluate the biological activity of the mefenamate anion entrapped into the LDH framework. Besides it was also prepared as a similar LDH structure but without a bioactive species, i.e. a Mg,Al-LDH material containing chloride anions between the layers (abbreviated LDH-Cl).

The LDHs materials ( $\mathrm{LDH}-\mathrm{Mef}$ and $\mathrm{LDH}-\mathrm{Cl}$ ) were synthesized by coprecipitation method as described in the literature $[27,28]$. The hybrid LDH-Mef sample was obtained using the $\mathrm{Mg}^{2+} / \mathrm{Al}^{3+}$ molar ratio equal to 2 and mefenamate/ $\mathrm{Al}^{3+}$ equal to 1 . $\mathrm{LDH}-\mathrm{Cl}$ was obtained using the same conditions but in the absence of the drug.

Initially, the $\mathrm{pH}$ of the aqueous solution of $0.1 \mathrm{~mol} / \mathrm{L}$ of mefenamic acid was adjusted to 10 by addition of $0.2 \mathrm{~mol} / \mathrm{L}$ of $\mathrm{NaOH}$. Under nitrogen atmosphere (to avoid carbonate ion formation by solubilization of carbon dioxide), a $0.1 \mathrm{~mol} / \mathrm{L}$ mixed solution of the divalent $\left(\mathrm{Mg}^{2+}\right)$ and trivalent $\left(\mathrm{Al}^{3+}\right.$ ) metal cations (in the chloride form) was added to the mefenamate solution. The $\mathrm{pH}$ value was kept at about 10 during the synthesis by the $\mathrm{NaOH}$ solution addition. The resulting slurry was aged with vigorous stirring for $1 \mathrm{~h}$ under $\mathrm{N}_{2}$ atmosphere at $25^{\circ} \mathrm{C}$. The solid was separated and washed with deionized water by filtration (to remove ions as sodium and chloride for example). Then the isolated solid was dried under reduced pressured at room temperature. 


\subsection{Physicochemical characterization}

X-ray diffraction patterns of powdered samples (PXRD) were recorded on a Rigaku Miniflex diffractometer, using $\mathrm{CuK}_{\alpha}$ radiation $\left(1.541 \AA, 30 \mathrm{kV}, 15 \mathrm{~mA}\right.$, scan step of $\left.0.03^{\circ}\right)$ and Ni filter. Elemental chemical analyses ( $\mathrm{C}, \mathrm{H}$, and $\mathrm{N}$ ) were performed using a Perkin Elmer 2400 analyzer at the Instituto de Química (Universidade de São Paulo USP). Thermogravimetric analysis and differential scanning calorimetry (TGA-DSC) were recorded on a Netzsch thermoanalyser TGA/DSC 490 PC Luxx, using a heating rate of $10^{\circ} \mathrm{C} / \mathrm{min}$ and under synthetic air flow rate of $50 \mathrm{~mL} / \mathrm{min}$.

Fourier transform infrared (FTIR) spectra of samples diluted in $\mathrm{KBr}$ were recorded on a Bomen spectrophotometer, model MB-102, with a coupled diffuse reflectance accessory (Pike Technologies, Inc.) in the $4000-400 \mathrm{~cm}^{-1}$ range. Fourier transform Raman (FT-Raman) spectra were recorded in a FT-Raman Bruker RFS-100/S spectrometer using $1064 \mathrm{~nm}$ exciting radiation (Nd:YAG laser Coherent Compass 1064-500 N) and a Ge detector. Laser power was kept below $20 \mathrm{~mW}$ to avoid sample degradation. Zeta potential and particle size were measured with Zetasizer NanoZS, Malvern Instruments, Worcestershire, UK.

DFT calculations were carried out for the isolated gas phase of the mefenamate anion (charge balanced by sodium cation) using the Gaussian 03 program and B3LYP hybrid functional [29]. The $6-311++G^{* *}$ basis set was used to perform the geometry optimizations and IR/Raman calculations. The calculated wavenumber values were scaled down by a single factor of 0.9679 , [30,31] used to accomplish with the anharmonicity of the fundamental frequencies in the vibrational spectra. Assignments of IR and Raman sodium mefenamate vibrational modes were obtained by visual inspection of displacement vectors.

\subsection{Hemolytic assay: cytotoxicity and membrane interaction evaluation}

Human red blood cells (approved by Ethics on Human Research Committee, UNICAMP, $0.15 \%$ hematocrit) were treated with mefenamic acid (MefH), LDH-Mef and LDH-Cl (1 to $90 \mathrm{mM}$, at 37 ${ }^{\circ} \mathrm{C}, 15 \mathrm{~min}$ ). After supernatant separation, the amount of hemoglobin released (412 nm) was expressed as the percent of hemolysis, as follows:

Hemolysis $\%=\left(A a-A c_{1} / A c_{2}-A c_{1}\right) \times 100$, where $A a$ is the absorbance of sample, $A c_{1}$ is the absorbance of $c_{1}$ (which is the phosphate buffered saline (PBS) solution) and $\mathrm{Ac}_{2}$ is the absorbance of $\mathrm{c}_{2}$ (which is water).

\subsection{Animals}

Male Swiss mice (20-30 g) were housed in cages in a temperaturecontrolled room. Each cage had available water and ad libitum food. All experimental protocols were performed in accordance with the Guide for Care and Use of Laboratory Animals (National Institute of Health, Bethesda, MD, USA) and were approved by the appropriate ethics committee (protocol no. 0066/10 and protocol no. 2262-1).

\subsection{Paw edema model}

The paw edema experiments were adapted and carried out as previously described by Chaves et al. [32] To induce edema with inflammatory agents, the mice received $50 \mu \mathrm{L}$ of carrageenan $(500 \mu \mathrm{g} / \mathrm{paw})$, dextran sulfate $(500 \mu \mathrm{g} / \mathrm{paw})$ or $\mathrm{PGE}_{2}(3.0 \mathrm{nmol} / \mathrm{paw})$ into the right hind paw (group I). Animals received MefH ( $31 \mu \mathrm{mol} / \mathrm{kg}$; group II), LDH-Mef ( $38 \mu \mathrm{mol}$ of $\mathrm{Mef} / \mathrm{kg}$; group III) or LDH-Cl (group IV) intraperitoneally (i.p.) 30 min before injection of inflammatory agents. The volume of the right hind paw was measured with an Ugo Basile plethysmometer, before $\left(V_{0}\right)$ and different times after inflammatory stimuli $\left(V_{t}\right)$. The effect of pretreatments was calculated as percent inhibition of edema relative to the paw volume of the inflammatory agents-treated groups using the following formula:

$\%$ inhibition of edema $=\frac{\left(\mathrm{V}_{\mathrm{t}}-\mathrm{V}_{0}\right) \text { Control }-\left(\mathrm{V}_{\mathrm{t}}-\mathrm{V}_{0}\right) \text { Treated }}{\left(\mathrm{V}_{\mathrm{t}}-\mathrm{V}_{0}\right) \text { Control }} \times 100$

\subsection{Myeloperoxidase activity (MPO)}

Briefly, 50-100 mg of paw tissue was homogenized in potassium buffer containing $0.5 \%$ hexadecyltrimethylammonium bromide (HTAB). The samples were centrifuged at $4500 \mathrm{rpm}$ for $15 \mathrm{~min}$ at $4{ }^{\circ} \mathrm{C}$. The pellet was resuspended and MPO activity was assayed by measuring the change in absorbance at $450 \mathrm{~nm}$ using o-dianisidinedihydrochloride and 1\% hydrogen peroxide. MPO activity was reported as units/mg of tissue. A unit of MPO activity was defined as that converting $1 \mu \mathrm{mol}$ of hydrogen peroxide to water in $1 \mathrm{~min}$ at $22^{\circ} \mathrm{C}$.

\subsection{Evaluation of neutrophil migration}

Prior to injection with $250 \mu \mathrm{L}$ of carrageenan ( $500 \mu \mathrm{g} / \mathrm{cavity}$ ), the animals were pretreated with saline (Sal), MefH ( $31 \mu \mathrm{mol} / \mathrm{kg}$ ), LDH-Mef ( $38 \mu \mathrm{mol}$ of Mef $/ \mathrm{kg}$ ) or LDH-Cl samples. $4 \mathrm{~h}$ later, mice were euthanized and the peritoneal cavity was washed with $1.5 \mathrm{~mL}$ of heparinized phosphate buffered saline to harvest peritoneal cells. Total leucocytes counts were performed in a Neubauer chamber, and neutrophil counts (100 cells total) were carried out on cytocentrifuge slides stained with hematoxylin and eosin. The results are presented as the number of neutrophils per $\mathrm{mL}$ of peritoneal exudate.

\subsection{Mechanical hypernociception}

Initially, the animals were pretreated intraperitoneally with saline (Sal), MefH (31 $\mu \mathrm{mol} / \mathrm{kg}$ ), LDH-Mef (38 $\mu \mathrm{mol}$ of Mef $/ \mathrm{kg}$ ) or LDH-Cl samples. 30 min later, the hyperalgesia was induced with $50 \mu \mathrm{L}$ of carrageenan $(500 \mu \mathrm{g} / \mathrm{paw})$ into the right hind paw and measured by the paw pressure test as previously described by Cunha et al. [33]. A digital analgesiometer (Insight ${ }^{\circledR}$, Brazil) with a cone-shaped, rounded tip paw-presser was used to apply a linearly increasing force to the right hind paw of the mice. The nociceptive threshold was measured in the right hind paw and determined by the average of 3 consecutive trials recorded before (zero time) and $3 \mathrm{~h}$ and $4 \mathrm{~h}$ after carrageenan injection (peak effect). Hyperalgesia was calculated from the difference between these 2 averages ( $\Delta$ of nociceptive threshold) and expressed in grams. To reduce stress, the mice were habituated to the apparatus 1 day prior to the experiments.

\subsection{Acetic acid-induced writhings}

Male Swiss mice (25-30 g, $n=6 /$ group) were treated by oral route with $\mathrm{NaCl} 0.9 \%$ solution (control), mefenamic acid (MefH) and LDH-Mef $(50,100,200 \mathrm{mg} / \mathrm{kg})$, before the intraperitoneal injection of $0.6 \%$ of acetic acid $(0.1 \mathrm{~mL} / 10 \mathrm{~g})$. The antinociceptive activity was evaluated by the number of writhings during a $20 \mathrm{~min}$ period [34].

\subsection{Statistical analysis}

Results are expressed as mean \pm SEM from at least 5-6 animals per group and statistical analysis was performed using one-way analysis of variance (ANOVA) followed by the Newman-Keuls post hoc test, when appropriate. Statistical significance was set at $p<0.05$. 


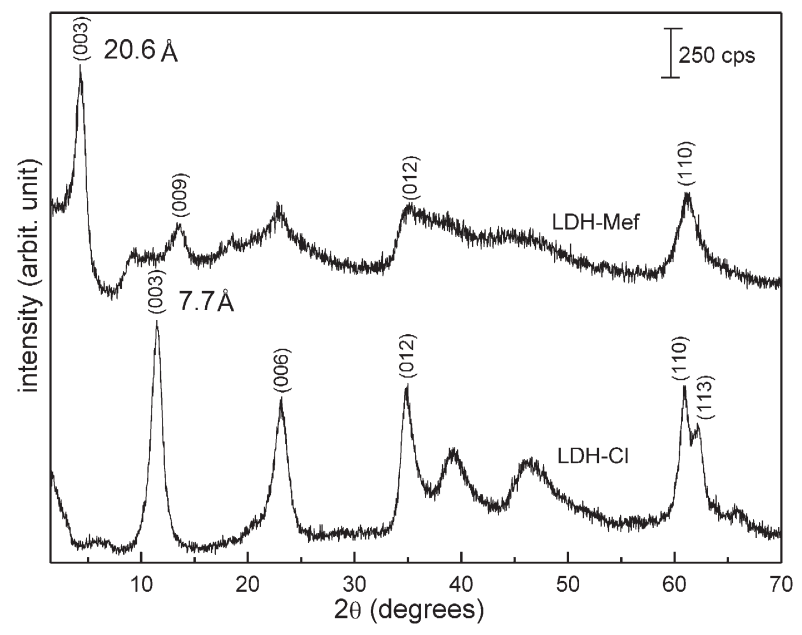

Fig. 2. PXRD patterns of LDH-Mef and LDH-Cl.

\section{Results}

\subsection{Physicochemical characterization of LDH-Mef}

The process of the carrier system formation can be classified as a self-assembling phenomenon, in which the soluble metal cations and the hydroxide and bioactive anions interact by electrostatic forces forming organized 2D structures at nanometer scale. A general chemical equation can be written for the synthetic reaction applied in this work:

$2 \mathrm{MgCl}_{2}(\mathrm{aq})+\mathrm{AlCl}_{3}(\mathrm{aq})+6 \mathrm{NaOH}(\mathrm{aq})+\mathrm{NaMefenamate}(a q) \rightarrow$ $\left[\mathrm{Mg}_{2} \mathrm{Al}(\mathrm{OH})_{6}\right][$ Mefenamate $](s)+7 \mathrm{NaCl}(\mathrm{aq})$.

According to the elemental analysis ( $\mathrm{CHN}$ ) data, metal contents, and the percentage of $\mathrm{H}_{2} \mathrm{O}$ (obtained from TGA curve) shown in Supplementary Material (Table SI), the chemical composition of LDH-Mef material is
$\left[\mathrm{Mg}{ }_{2} \mathrm{Al}(\mathrm{OH})_{6}\right]\left(\mathrm{C}_{15} \mathrm{H}_{14} \mathrm{NO}_{2}\right)_{0.6} \mathrm{Cl}_{0.4} \cdot 2 \mathrm{H}_{2} \mathrm{O}$, indicating a $40.3 \%(w / w)$ drug concentration in the carrier system. The co-intercalation of chloride anions (coming from metal cation salts) is proposed to also neutralize the positive LDH layers (see discussion below).

PXRD patterns of LDH-Mef and LDH-Cl samples are shown in Fig. 2. The displacement of the (003) LDH-Mef diffraction peak (related to the basal spacing of the layered material in Fig. $1 \mathrm{~A}$ ) to a low angle $(2 \theta)$ region when compared to $\mathrm{LDH}-\mathrm{Cl}$, indicating the drug intercalation, can be noticed. The $\mathrm{d}_{003}$ value increases from $7.7 \AA$, for the $\mathrm{LDH}-\mathrm{Cl}$, to $20.6 \AA$, for the hybrid LDH-Mef.

The 15.8 A interlayer distance, which is obtained by the difference of the $\mathrm{d}_{003}$ basal spacing (20.6 $\AA$ ) and the thickness of the inorganic layer ( $4.8 \AA$ ), suggests a bilayer disposition of the drug in the interlayer region. If a monolayer is formed, a maximum basal spacing of around 14.6 Å can be expected (since mefenamate anion dimensions are estimated by DFT calculations to be of the order of $9.80 \AA \times 9.00 \AA \times 6.65 \AA$ in Fig. 1B). Previous reports concerning the intercalation of mefenamate anion into LDHs also have proposed a bilayer arrangement $\left(\mathrm{d}_{003}\right.$ value varied from 21.3 to $22.5 \AA$ ) $[25,26,35]$.

The layer charge density of $\mathrm{LDH}$ with $\mathrm{Mg} / \mathrm{Al}$ molar ratio equal 2 is around $25 \AA^{2}$ /electric charge, [27] whereas mefenamate monoanion displays an area of $60 \AA^{2}(9.00 \AA \times 6.65 \AA)$, projected on the inorganic sheet, when intercalated perpendicularly, to maximize the interactions between the carboxylate group and the positive layers. Thus, it can be seen that mefenamate monoanion is too large and unable to compensate one LDH positive charge. Therefore the presence of chloride anions in the interlayer region is necessary, in order to balance the layer's charge. It is worth to notice that a monovalent anion neutralizes a positive charge on one layer side; hence there is a free area on the other side of the layer [36]. Considering the area per electric charge of mefenamate ion $\left(60 \AA^{2}\right)$ and the chloride anion area $\left(10 \AA^{2}\right)$, [37] a drug orientation as shown in Fig. 3 may be proposed . In this schematic representation, ten positive charges per $c a .250 \AA^{2}$ area of LDH layer are shown. The neutralization of these ten positive charges can be obtained with six mefenamate ions in a double layer arrangement, as mentioned above, surrounded by four chloride ions. The chemical analysis corroborated the arrangement
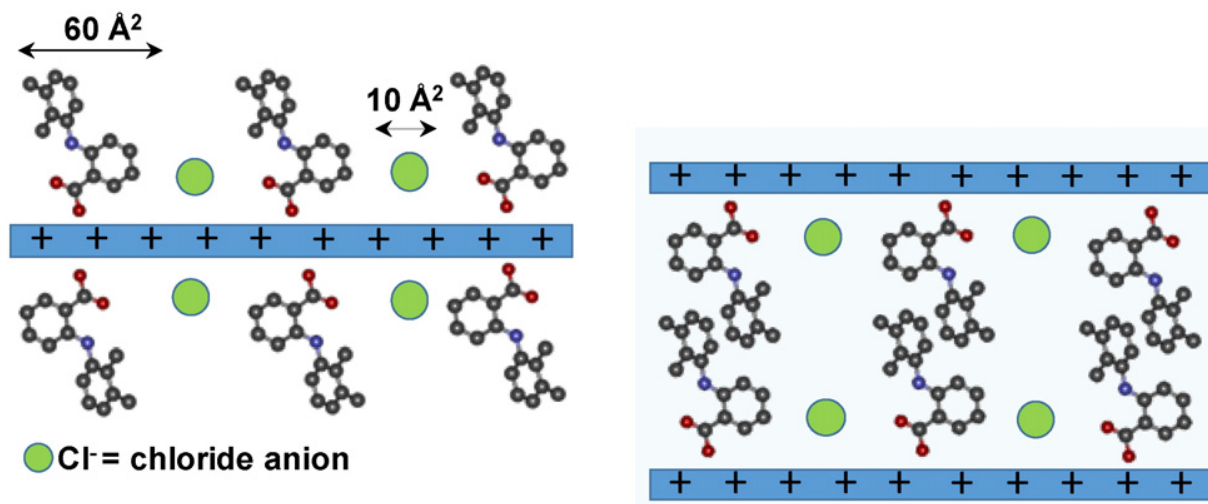

(A)
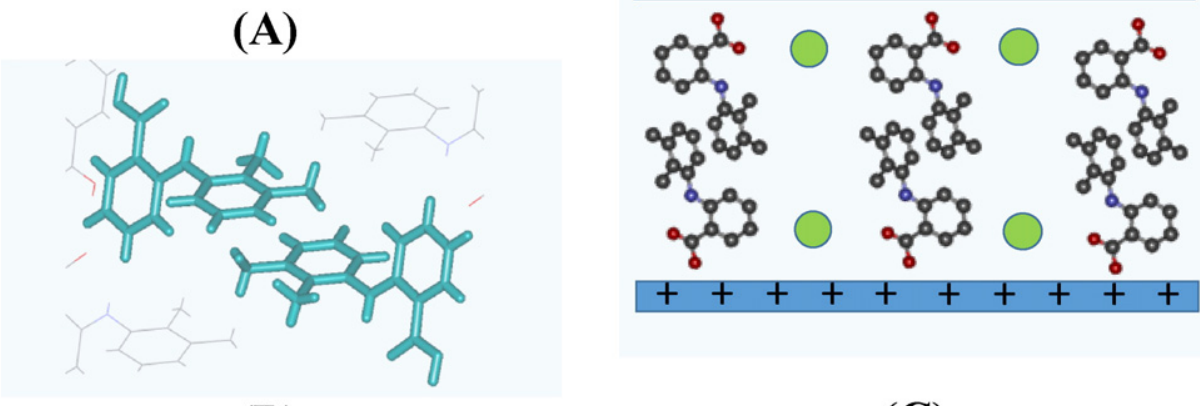

(B)

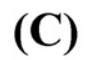

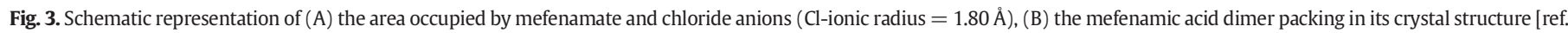
38 ] and $(C)$ the proposed bilayer arrangement of the mefenamate anions between the layers. 
of the interlayer content, i.e., each layer's positive charge is balanced by $0.6 \mathrm{Mef}$ ion and $0.4 \mathrm{Cl}^{-}$ion. Moreover, the arrangement of the organic ions between the layers, should be interdigitated since the higher dimension of mefenamate is $9.8 \AA$

In order to suggest an arrangement for the mefenamate interdigitated bilayer, the disposition of the free mefenamic acid molecule in its crystal was taken into account, since we have observed that the pravastatin drug orientation between LDH layers (determined by 1D plot) is in close relation to its packing in the pravastatin tert-octyl ammonium salt [27]. Mefenamic acid exists as a dimer in the solid state and adjacent pairs of molecules interact through the dimethylphenyl rings, Fig. 3B [38]. It is assumed that, even inside the layers, the drug is present in a similar state to that observed in MefH crystal (which provides the lowest energy packing), i.e., an interdigitated arrangement as proposed in Fig. 3, C.

Considering that mefenamic acid is intercalated in the anionic form, its sodium salt was prepared (see Supplementary Material) for comparison purposes. First the IR and Raman vibrational spectra of sodium mefenamate (NaMef) were calculated and compared to the experimental ones (Fig. 4A and B, respectively). The theoretical (species in vacuum) and the experimental (ions in solid state) spectra of NaMef are in good agreement, in spite of the different conditions. The vibrational wavenumbers calculated in the DFT framework are shown in Table 1. The bands assignments were made by visual inspection based on the experimental and calculated spectral data, obtained for mefenamic acid [39]. Comments about vibrational spectra of NaMef are made in the Supplementary Material, as well as, the analysis of FT-IR and FT-Raman spectra of LDH-Mef carrier. According to the spectral data, the chemical integrity of the guest drug within the LDH layers is kept after the immobilization process.

The aqueous suspension of the nanocarrier LDH-Mef presents low tendency towards agglomeration (zeta potential equal to $+36.3 \mathrm{mV}$ ) and a hydrodynamic average diameter of $132 \mathrm{~nm}$. Del Arco et al. [25] obtained a mean diameter of $350 \mathrm{~nm}$ for a similar system. The LDH-Cl aqueous suspension is highly stable (zeta potential equal to $+41.7 \mathrm{mV}$ ) with a hydrodynamic average diameter of $85 \mathrm{~nm}$. Particle size, as well as, the stability against agglomeration of the nanomaterial LDH is directly connected with its bioavailability, more specifically intracellular uptake [20]. Oh et al. [18] showed that the uptake of the LDH-carbonate materials coated with fluorescein 5 '-isothiocyanate dye (FTIC) was dependent on particle size. Particles with size in the 50 and $200 \mathrm{~nm}$ range were taken up by clathrin-mediated endocytotic mechanism [18]. It is postulated that both LDH-Cl and LDH-Mef nanomaterials in this study are in the ideal size interval for optimum intracellular delivery.

\subsection{Hemolysis Assay}

In order to evaluate the cytotoxic effect of MefH and LDH-Mef, red blood cells were used as a model for monitoring the membrane interaction expressed as the percentage of hemoglobin released in a concentration range from 0.5 to $100 \mathrm{mM}$ (Fig. 5) in all formulations. The hemolytic concentration curve for MefH was observed up to $7.5 \mathrm{mM}$ with maximum $20 \%$ of hemolysis due to its limited aqueous solubility. However, for $\mathrm{LDH}-\mathrm{Cl}$ and $\mathrm{LDH}-\mathrm{Mef}$, hemolytic effects were observed at higher concentrations, such as 72 and $92 \mathrm{mM}$. The concentrations for the onset of hemolysis (Conset) in the cases of MefH, LDH and LDH-Mef were, respectively, $0.5 \mathrm{mM}, 1.66 \mathrm{mM}$ and $1.83 \mathrm{mM}$. Similar results were also observed at $20 \%$ of hemolysis with $7.5,23.3$ and $11 \mathrm{mM}$ for $\mathrm{MefH}, \mathrm{LDH}-\mathrm{Cl}$ and LDH-Mef. Our results indicated that the entrapment of the mefenamate anion in LDH nanoparticles decreased the hemolytic effects, as observed by the higher hemolytic concentrations measured for LDH-Mef, when compared to MefH $(1.46$ times, $p<0.01$ ) at the same point (Fig. 5).

\subsection{Effect of LDH-Mef nanoparticles in the paw edema model}

Fig. 6 shows that the injection of the inflammatory agents carrageenan (paw volume: $0.066 \pm 0.006 \mathrm{~mL}$; Fig. $6 \mathrm{~A})$, dextran sulfate $(0.068 \pm$

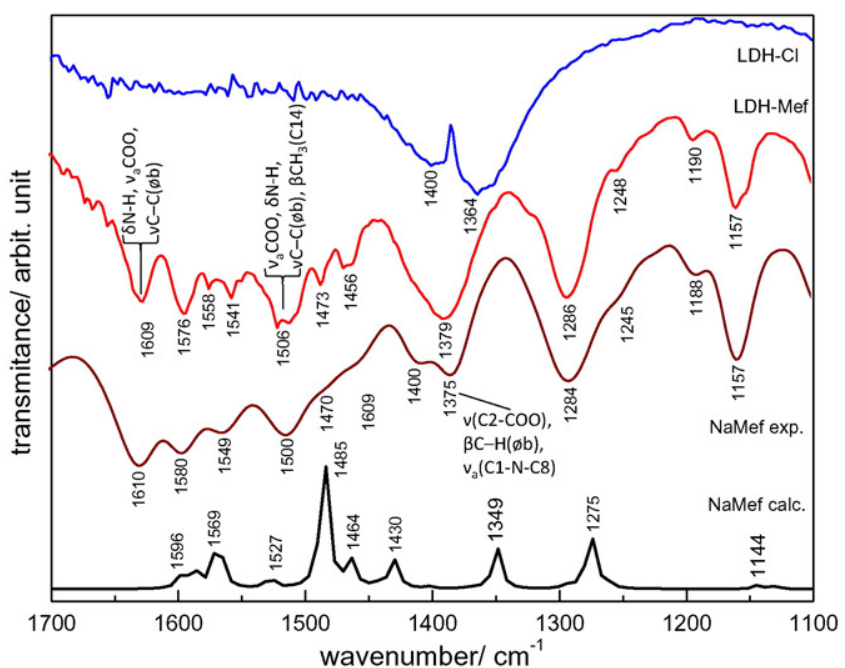

(A)

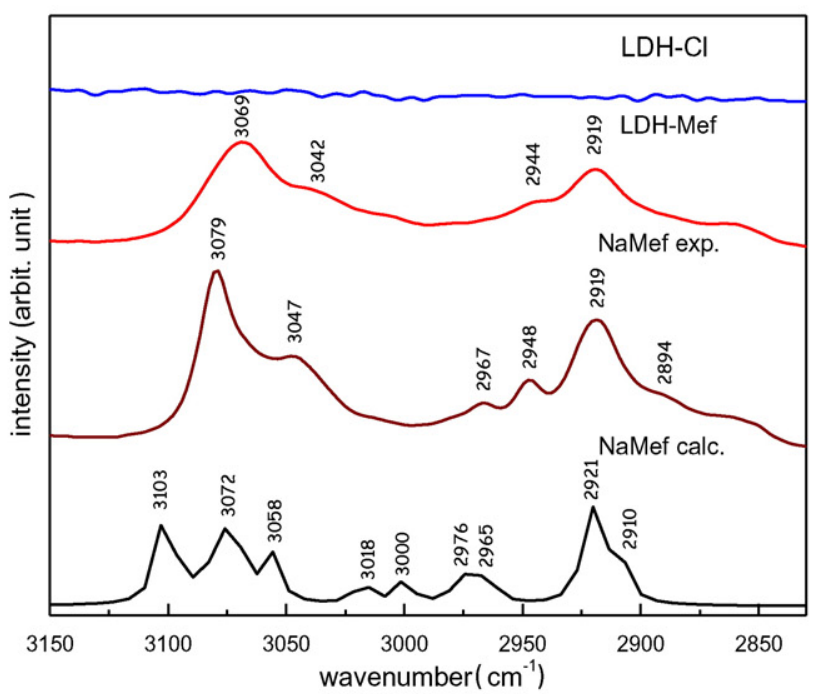

(B1)

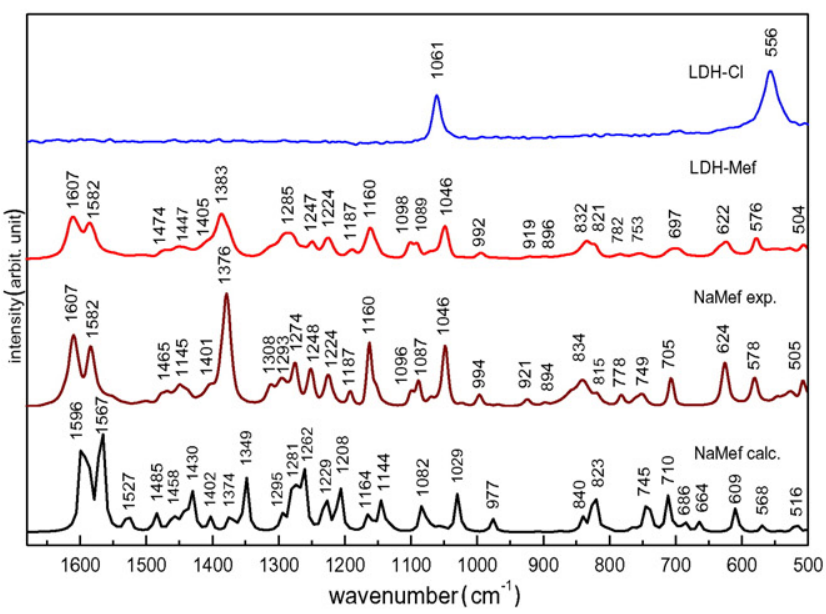

(B2)

Fig. 4. (A) FT-IR spectra of calculated and experimental NaMef and LDH-Mef in the $1700-1100 \mathrm{~cm}^{-1}$ region. (B) FT-Raman spectra of calculated and experimental NaMef and LDH-Mef. Related to the region at (B1) $3200-2800 \mathrm{~cm}^{-1}$ and (B2) $1700-500 \mathrm{~cm}^{-1}$. For comparison purposes, spectrum of $\mathrm{LDH}-\mathrm{Cl}$ was inserted. 
Table 1

FT-Raman and FT-IR wavenumbers (in $\mathrm{cm}^{-1}$ ) of NaMef and LDH-Mef in solid state, calculated vibrational wavenumbers (in $\mathrm{cm}^{-1}$ ), and tentative assignments.

\begin{tabular}{|c|c|c|c|c|c|}
\hline \multicolumn{3}{|l|}{ NaMef } & \multirow{2}{*}{\multicolumn{2}{|c|}{$\frac{\text { LDH-Mef }}{\text { Experimental }}$}} & \multirow[t]{3}{*}{ Assignment ${ }^{\mathrm{c}, \mathrm{d}}$} \\
\hline \multicolumn{2}{|c|}{ Experimental } & \multirow[t]{2}{*}{ Calculated $^{\mathrm{a}, \mathrm{b}}$} & & & \\
\hline Raman & IR & & Raman & IR & \\
\hline 3079 & & 3103 & 3069 & & $\nu \mathrm{C}-\mathrm{H}$ in phase $(ø \mathrm{~b})$ \\
\hline shoulder & & 3072 & Shoulder & & $\nu \mathrm{C}-\mathrm{H}$ in phase (øa) \\
\hline 3047 & & 3058 & 3042 & & $\nu \mathrm{C}-\mathrm{H}$ trigonal $(ø \mathrm{~b})$ \\
\hline & & 3018 & & & $v_{\mathrm{a}} \mathrm{CH}_{3}(\mathrm{C} 14)$ \\
\hline & & 3000 & & & $v_{\mathrm{a}} \mathrm{CH}_{3}(\mathrm{C} 15)$ \\
\hline 2967 & & 2976 & & & $v_{\mathrm{a}} \mathrm{H}-\mathrm{C}-\mathrm{H}(\mathrm{C} 14)$ \\
\hline 2948 & & 2965 & 2944 & & $\nu_{\mathrm{a}} \mathrm{H}-\mathrm{C}-\mathrm{H}(\mathrm{C} 15)$ \\
\hline 2919 & & 2921 & 2919 & & $\nu_{\mathrm{s}} \mathrm{CH}_{3}(\mathrm{C} 15)$ \\
\hline 2894 & & 2910 & Shoulder & & $v_{\mathrm{s}} \mathrm{CH}_{3}(\mathrm{C} 14)$ \\
\hline 1607 & 1610 & 1596 & 1607 & 1609 & $\delta \mathrm{N}-\mathrm{H}, v_{\mathrm{a}} \mathrm{COO}, \nu \mathrm{C}-\mathrm{C}(ø \mathrm{~b})$ \\
\hline & 1580 & 1569 & & 1576 & $\delta \mathrm{N}-\mathrm{H}, \nu \mathrm{C}-\mathrm{C}(\varnothing \mathrm{a}, \varnothing \mathrm{b})$ \\
\hline 1582 & & 1567 & 1582 & & $\nu \mathrm{C}-\mathrm{C}(\varnothing \mathrm{a}), \mathrm{\beta CH}_{3}(\mathrm{C} 14)$ \\
\hline & 1549 & 1527 & & 1541 & $\nu_{\mathrm{a}} \mathrm{COO}, \delta \mathrm{N}-\mathrm{H}, \nu \mathrm{C}-\mathrm{C}(\varnothing \mathrm{b})$ \\
\hline & 1500 & 1485 & & 1506 & $\begin{array}{l}\nu_{\mathrm{a}} \mathrm{COO}, \delta \mathrm{N}-\mathrm{H}, \nu \mathrm{C}-\mathrm{C} \\
(ø \mathrm{~b}), \mathrm{BCH}_{3}(\mathrm{C} 14)\end{array}$ \\
\hline & $\sim 1470$ & 1464 & 1474 & 1473 & $\begin{array}{l}\delta \mathrm{CH}_{3}(\mathrm{C} 14, \mathrm{C} 15), \beta \mathrm{C}-\mathrm{H} \\
(ø \mathrm{a})\end{array}$ \\
\hline 1465 & & 1458 & & & $\begin{array}{l}\delta \mathrm{CH}_{3}(\mathrm{C} 14, \mathrm{C} 15), \beta \mathrm{C}-\mathrm{H} \\
(\varnothing \mathrm{a}, \varnothing \mathrm{b})\end{array}$ \\
\hline 1445 & $\sim 1445$ & 1430 & 1447 & $1456-1448$ & $\begin{array}{l}\delta \mathrm{CH}_{3}(\mathrm{C} 14, \mathrm{C} 15), \delta \mathrm{N}-\mathrm{H}, \\
\beta \mathrm{C}-\mathrm{H}(\varnothing \mathrm{a}, \varnothing \mathrm{b})\end{array}$ \\
\hline 1401 & 1400 & 1374 & 1405 & $\sim 1400$ & $\delta \mathrm{CH}_{3}(\mathrm{C} 14, \mathrm{C} 15)$ \\
\hline 1376 & 1375 & 1349 & 1383 & 1379 & $\begin{array}{l}\nu(\mathrm{C} 2-\mathrm{COO}), \beta \mathrm{C}-\mathrm{H}(\varnothing \mathrm{b}) \\
v_{\mathrm{a}}(\mathrm{C} 1-\mathrm{N}-\mathrm{C} 8)\end{array}$ \\
\hline 1308 & & 1295 & & & $\begin{array}{l}\nu_{\mathrm{a}}(\mathrm{C} 1-\mathrm{N}-\mathrm{C} 8), \nu \mathrm{C}-\mathrm{C} \\
(ø \mathrm{a}, \varnothing \mathrm{b})\end{array}$ \\
\hline 1293 & & 1281 & & & $\beta C-H(ø a, ø b)$ \\
\hline & 1284 & 1275 & & 1286 & $\begin{array}{l}\nu(\mathrm{C} 2-\mathrm{COO}), v \mathrm{C}-\mathrm{C} \\
(ø \mathrm{a}, \varnothing \mathrm{b}), \nu_{\mathrm{a}}(\mathrm{C} 1-\mathrm{N}-\mathrm{C} 8)\end{array}$ \\
\hline 1274 & & 1262 & $\sim 1280$ & & $\begin{array}{l}\nu \mathrm{C}-\mathrm{C}(\varnothing \mathrm{a}, \varnothing \mathrm{b}) \\
\nu_{\mathrm{a}}(\mathrm{C} 1-\mathrm{N}-\mathrm{C} 8)\end{array}$ \\
\hline 1248 & $\sim 1245$ & 1229 & 1247 & 1248 & $\nu \mathrm{C}-\mathrm{C}(\varnothing \mathrm{a}), \beta \mathrm{C}-\mathrm{H}(\varnothing \mathrm{a})$ \\
\hline 1224 & & 1208 & 1224 & & $\delta \mathrm{N}-\mathrm{H}, \beta \mathrm{C}-\mathrm{H}(\varnothing \mathrm{b})$ \\
\hline 1187 & 1188 & 1164 & 1187 & 1190 & $\begin{array}{l}\nu(C 14-C 9), \nu C-C(\varnothing a) \\
\beta C-H(ø a)\end{array}$ \\
\hline 1160 & 1157 & 1144 & 1160 & 1157 & $\beta C-H(ø b)$ \\
\hline $\begin{array}{l}1096 \\
1087\end{array}$ & & 1082 & $\begin{array}{l}1098 \\
1089\end{array}$ & & $\begin{array}{l}\beta C-\mathrm{H}(\varnothing \mathrm{a}), \delta \mathrm{CH}_{3}(\mathrm{C} 14, \\
\mathrm{C} 15)\end{array}$ \\
\hline 1046 & & 1029 & 1046 & & $v \mathrm{C}-\mathrm{C}(\varnothing \mathrm{b})$ \\
\hline 994 & & 977 & 992 & & $\mathrm{wCH}_{3}(\mathrm{C} 15)$ \\
\hline 834 & & 840 & 832 & & $\begin{array}{l}\mathrm{sc}(\mathrm{COO}), v(\mathrm{C} 2-\mathrm{C} 7), \delta \\
\text { trigonal } \mathrm{C}-\mathrm{C}-\mathrm{C}(\varnothing \mathrm{b})\end{array}$ \\
\hline 815 & & 823 & 821 & & $\begin{array}{l}\mathrm{sc}(\mathrm{COO}), \mathrm{C}-\mathrm{C}-\mathrm{C} \text { in } \\
\text { phase puckering } \\
(ø a, ø b), \gamma(\mathrm{C} 1-\mathrm{N}-\mathrm{C} 8)\end{array}$ \\
\hline 778 & & 764 & 782 & & $\gamma \mathrm{C}-\mathrm{H}$ in phase (øa) \\
\hline 749 & & 745 & 753 & & $\gamma \mathrm{C}-\mathrm{H}$ in phase $(\varnothing \mathrm{a}, \varnothing \mathrm{b})$ \\
\hline 705 & & 710 & 697 & & $\gamma \mathrm{N}-\mathrm{H}$ \\
\hline 624 & & 609 & 622 & & $\begin{array}{l}\beta C-C-C(ø b), \text { breathing } \\
(ø a)\end{array}$ \\
\hline 578 & & 568 & 576 & & $\beta C-C-C(ø a, ø b)$ \\
\hline 505 & & 516 & 504 & & $\beta C-C-C(\varnothing a), r(C O O)$ \\
\hline
\end{tabular}

a Selected values in $\mathrm{cm}^{-1}$ obtained by functional/basis set B3LYP/6-311 $++\mathrm{G}^{* *}$.

b The wavenumbers are shifted by 0.9679 , according to the literature ${ }^{30}$.

c Main groups involved in the vibration. $v_{\mathrm{s}}=$ symmetric stretching, $v_{\mathrm{a}}=$ antisymmetric stretching, $\delta=$ bending, $s c=$ scissoring, $w=$ wagging, $\beta=$ bending in plane, $\gamma=$ bending out of plane, $r=$ rocking.

d The numbers and letters are related to the carbon indexation in the structure shown in Fig. 1B.

$0.006 \mathrm{~mL}$; Fig. 6B) or $\mathrm{PGE}_{2}(0.042 \pm 0.002 \mathrm{~mL}$; Fig. 6C) promoted paw edema with the maximum peak effect after approximately $3 \mathrm{~h}, 30 \mathrm{~min}$ and $15 \mathrm{~min}$, respectively. Pretreatment with $\mathrm{MefH}(31 \mu \mathrm{mol} / \mathrm{kg})$ or LDH-Mef nanoparticles ( $38 \mu \mathrm{mol}$ of $\mathrm{Mef} / \mathrm{kg}$ ) effectively inhibited the edema $3 \mathrm{~h}$ after the injection of carrageenan $(80.86 \%$ and $83.50 \%$ inhibition, respectively; Fig. 6A). Similarly, pretreatment with MefH

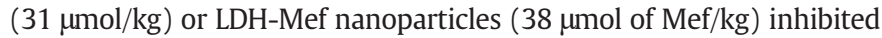
edema induced by dextran sulfate after 30 min $(82.32 \%$ and $78.92 \%$
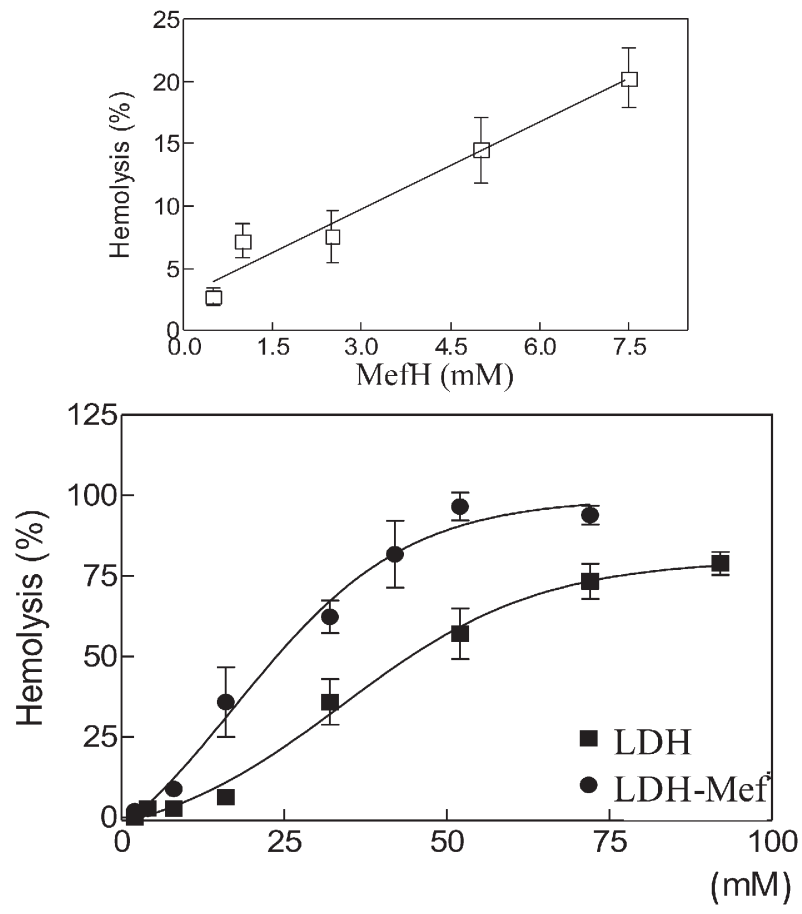

Fig. 5. Hemolytic effects of MefH, $\mathrm{LDH}-\mathrm{Cl}$ and $\mathrm{LDH}-\mathrm{Mef}$ on human erythrocytes (Hematocrit $0.15 \%, \mathrm{pH} 7.4,37^{\circ} \mathrm{C}, \mathrm{n}=4-6$, mean $\pm \mathrm{SD}$ ).

inhibition, respectively; Fig. 6B) and $\mathrm{PGE}_{2}$ after $15 \mathrm{~min}$ (90.10\% and 93.70\% inhibition, respectively; Fig. 6C). On the other hand, $\mathrm{LDH}-\mathrm{Cl}$ did not significantly affect the paw edema evoked by any of the inflammatory agents. This result may indicate that the $\mathrm{LDH}$ matrix did not aggravate the inflammatory condition or, in other words, the inorganic carrier indeed seems to be biocompatible.

\subsection{Myeloperoxidase activity}

Fig. 6D shows that the pretreatment with MefH $(31 \mu \mathrm{mol} / \mathrm{kg})$ or LDH-Mef nanoparticles ( $38 \mu \mathrm{mol}$ of $\mathrm{Mef} / \mathrm{kg}$ ) reduced the MPO activity to $6.3 \pm 0.9 \mathrm{U} / \mathrm{mg}$ and $5.6 \pm 0.8 \mathrm{U} / \mathrm{mg}$ of tissue, respectively, as compared to the carrageenan group ( $16.3 \pm 1.7 \mathrm{U} / \mathrm{mg}$ of tissue).

\subsection{Peritonitis induced by carrageenan}

The total leukocyte count in the peritoneal cavity of the carrageenan group was $8225 \times 10^{3} \pm 263 \times 10^{3}$ cells/mL (Fig. 6E). Administration of MefH $(31 \mu \mathrm{mol} / \mathrm{kg})$ or LDH-Mef nanoparticles (38 $\mu \mathrm{mol}$ of Mef $/ \mathrm{kg}$ ) significantly reduced the peritoneal leukocyte count to $3175 \pm$ $443 \times 10^{3}$ cells $/ \mathrm{mL}$ and $2638 \pm 402 \times 10^{3}$ cells $/ \mathrm{mL}$, respectively (Fig. 6E). In addition, the MefH or LDH-Mef nanoparticles also significantly reduced neutrophil migration $\left(1594 \pm 231 \times 10^{3}\right.$ cells $/ \mathrm{mL}$ and $562 \pm$ $104 \times 10^{3}$ cells/mL, respectively; Fig. $\left.6 \mathrm{~F}\right)$, as compared to carrageenan group $\left(4630 \times 10^{3} \pm 351 \times 10^{3}\right.$ cells $\left./ \mathrm{mL}\right)$. However, the $\mathrm{LDH}-\mathrm{Cl}$ sample did not significantly change cell migration.

\subsection{Hypernociception induced by carrageenan}

As shown in Fig. 7A, pretreatment with $\mathrm{MefH}(31 \mu \mathrm{mol} / \mathrm{kg})$ or LDH-Mef nanoparticles ( $38 \mu \mathrm{mol}$ of Mef $/ \mathrm{kg}$ ) significantly decreased hypernociception between 3 and $4 \mathrm{~h}$ after carrageenan administration.

\subsection{Writhings assay}

Fig. 7B shows that the treatment with LDH-Mef nanoparticles by oral administration reduced the number of writhings, enhancing the 
A

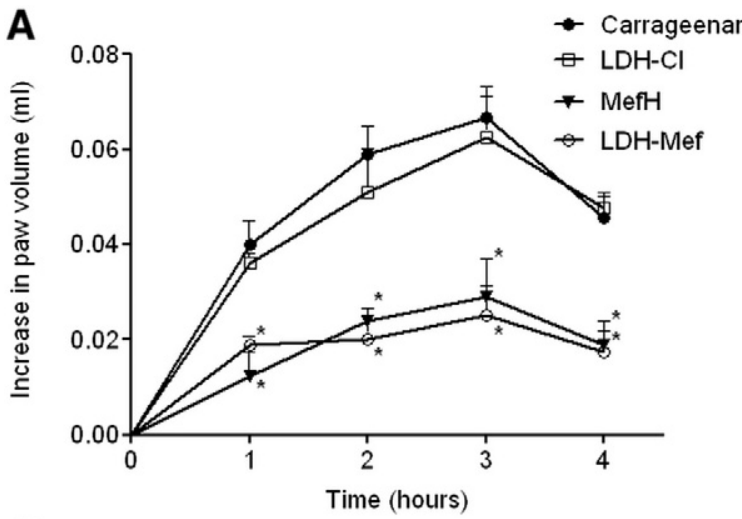

B

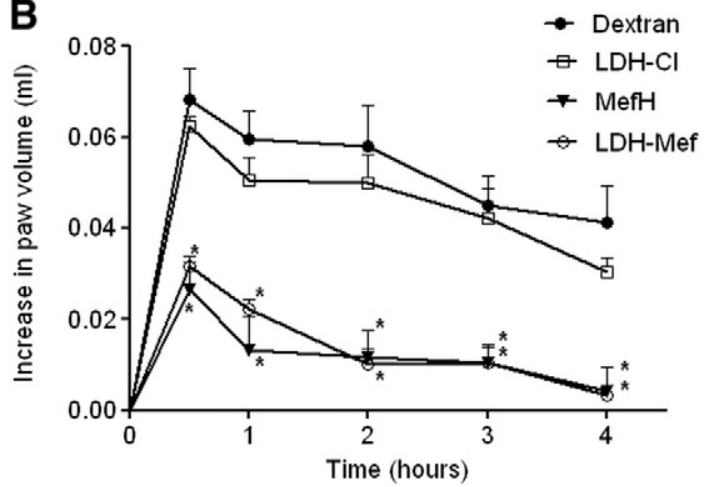

C

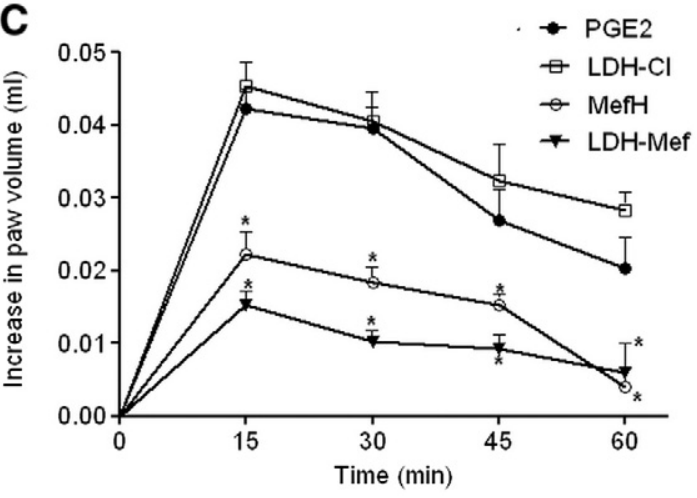

D

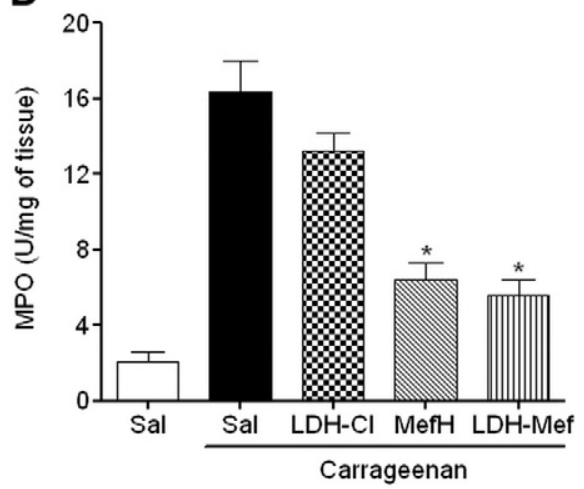

E

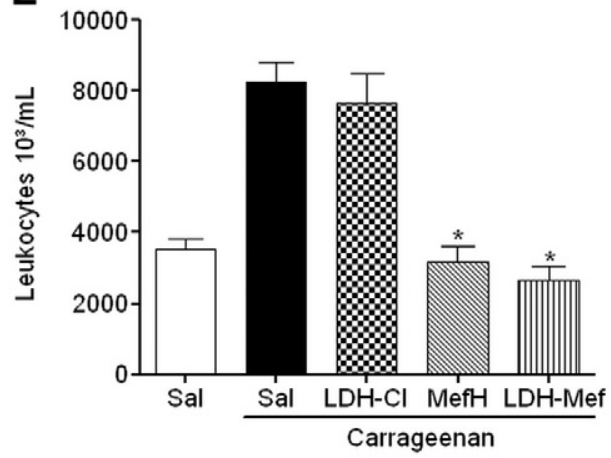

$\mathbf{F}$

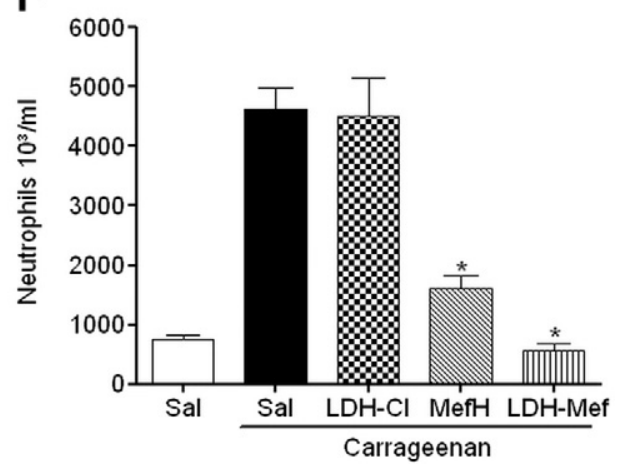

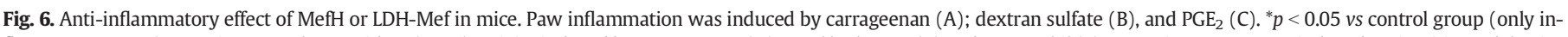

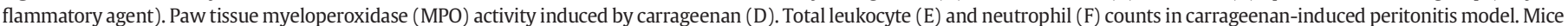

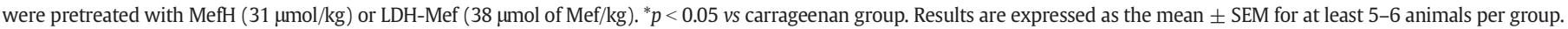

antinociceptive effect of MefH when compared to the non-intercalated $\mathrm{MefH}$, at three different doses $(\mathrm{p}<0.05)$.

\section{Discussion}

The present study was conducted to investigate the in vitro cytotoxicity using a membrane interaction model in red blood cells and the pharmacological potential actions of LDH-Mef nanoparticles. Several experimental models of inflammation (i.e. carrageenan-, dextran sulfate- and $\mathrm{PGE}_{2}$-induced paw edema, MPO activity and peritonitis) and nociception (i.e. mechanical hypernociception and acetic acidinduced writhing) were employed and LDH-Mef was compared with free MefH and LDH matrix without intercalated drug.

Reduced hemolytic effects after incorporation in nanocarriers have been reported in the literature for cyclodextrin inclusion complexes, [40] polymeric nanocapsules [41] and also for inorganic hydroxide nanoparticles. The mechanism of hemolysis involves the membrane interaction with a new drug or carrier candidates, and uptake of lipid components with changes on membrane fluidity [40]. In general, LDH nanoparticles did not induce pronounced cytotoxicity. For this reason, it was possible to observe that the intercalation of MefH in LDH reduced the hemolytic effects when compared to the non-intercalated MefH.

The carrageenan-induced paw edema is a model, widely used to characterize the mechanisms of action of anti-inflammatory compounds, including NSAIDs [42]. It is characterized by a biphasic process: initially the release of inflammatory mediators, such as histamine and serotonin, occurs followed by an increase in prostaglandin synthesis (mainly prostaglandin $\mathrm{E}_{2}\left(\mathrm{PGE}_{2}\right)$ ) and, subsequently, the rise in nitric oxide levels and the neutrophils infiltration is observed. On the other hand, the dextran sulfate promotes an osmotic edema characterized by an increase in the vascular permeability, induced by the release of vasoactive amines derived from mast cell degranulation [43]. Prostaglandins, particularly $\mathrm{PGE}_{2}$, are important pro-inflammatory mediators, which produce their edematogenic effect through the change of vascular permeability [44].

Pre-treatment with LDH-Mef nanoparticles produced an antiinflammatory efficacy, which is similar to the action observed for $\mathrm{MefH}$, in three different paw edema models used in this work. However, no significant efficacy difference between LDH-Mef nanoparticle and MefH was observed in acute inflammation model. The carrier without 


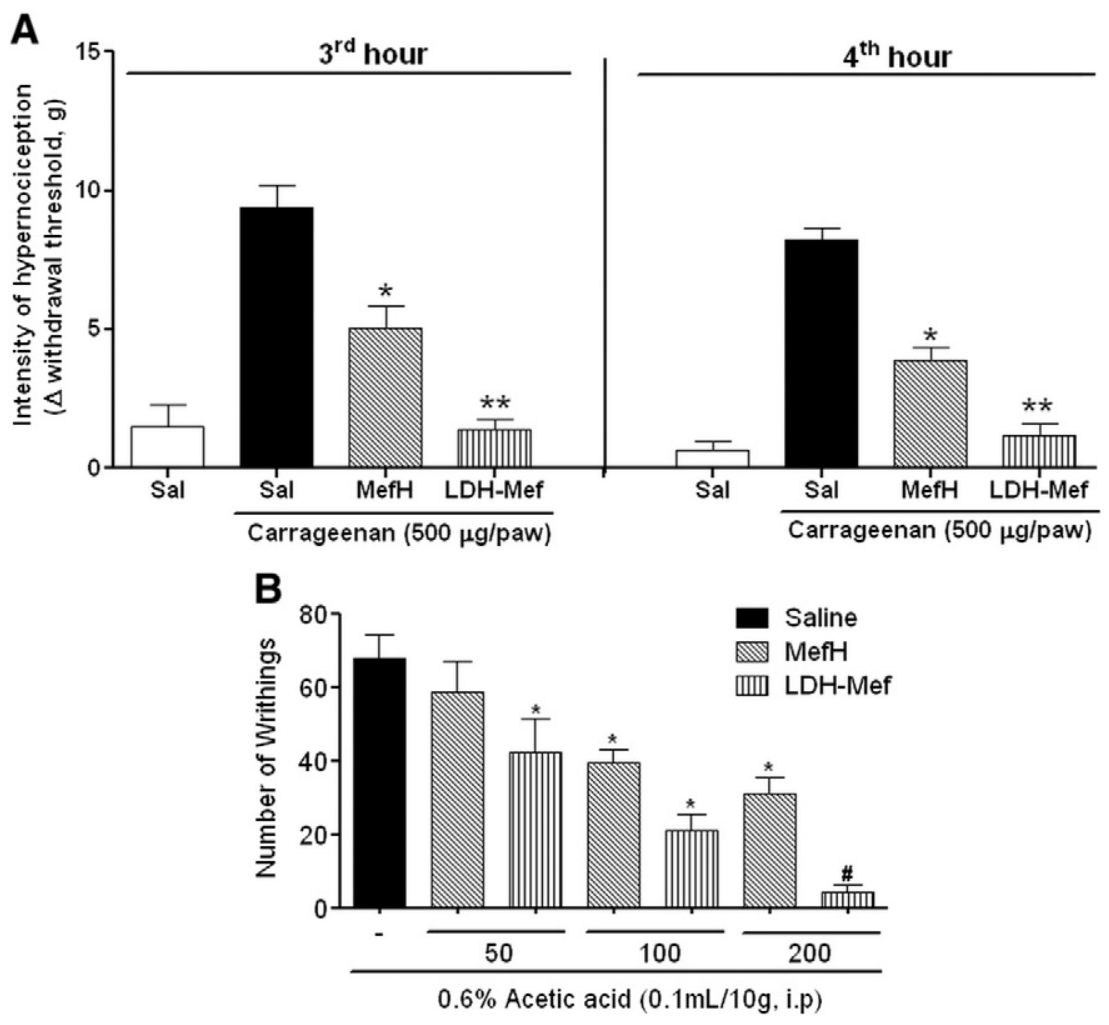

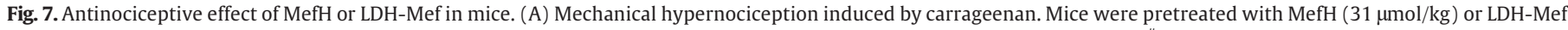

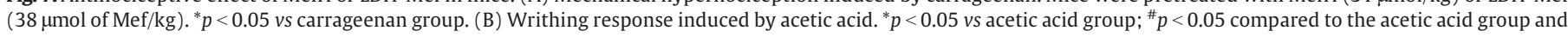
MefH $200 \mathrm{mg} / \mathrm{kg}$. Data are expressed as mean \pm S.E.M. of 5-6 animals for each group.

the drug (sample $\mathrm{LDH}-\mathrm{Cl}$ ) did not promote changes in edema induced by any inflammatory agents, applied in the tests.

Literature data have shown that treatment with anti-inflammatory drugs, such as dexamethasone, indomethacin and nimesulide inhibits cell migration to the inflammation site [45]. Thus, in view of the importance of cell migration in the inflammatory process, such as arthritis and sepsis, [46] we investigated whether the anti-inflammatory effects of MefH and LDH-Mef nanoparticle in carrageenan-induced paw edema model were associated with changes in cell migration. This mechanism was evaluated through the MPO activity and carrageenan-induced peritonitis.

MPO is a characteristic enzyme of neutrophil granules, released by inflammatory cells that act as an important indicator of the neutrophils' accumulation [47]. In the present study, MefH and LDH-Mef nanoparticle promoted an effective inhibitory effect on cell migration (MPO activity and peritonitis). The observed inhibition did not reveal any significant difference in the effect of the tested formulations. Moreover, compared to the carrageenan group, no changes were observed in these parameters for the animals treated with $\mathrm{LDH}-\mathrm{Cl}$.

Studies have shown that leukocyte migration to the inflamed site and release of several mediators are important characteristics of the inflammation, and are essential for the onset of tenderness and inflammatory pain [48]. Considering that NSAIDs also have antinociceptive effects, and based on the intimate relationship between inflammation and development of a painful sensation, we investigated the antinociceptive effect of MefH and LDH-Mef nanoparticles. For this purpose, carrageenaninduced mechanical hypernociception model and acetic acid-induced writhing were used.

Carrageenan is an inflammatory agent that is widely used for the investigation of the hypernociception in animal models. When administrated intraplantarly, this substance promotes rapid release of several inflammatory mediators, such as mast cells products, neutrophil chemoattractant-1 responsible for stimulating the synthesis of prostaglandins, increasing the local flow and vascular permeability, culminating in an exacerbated sensitivity to mechanical and thermal stimuli as a response of nociceptive neurons [32].

In the present study it was demonstrated that MefH administration decreases the mechanical inflammatory hypernociception. However, this experimental model revealed that LDH-Mef nanoparticles presented a significantly higher efficacy in comparison to MefH. This effect may be, at least partly, due to the inhibition of the inflammatory mediators' release and the inhibition of the interaction among neutrophils and the cellular surface. Based on these results and on the literature data, it is also possible to infer that vascular permeability changes are promoted by the augmented synthesis of prostaglandins in inflammatory processes, which facilitates the targeting of the nanocapsules to the inflamed site, increasing the pain threshold and the drug efficiency.

In the model of acetic acid-induced writhing, the injection of acetic acid in the peritoneal cavity causes a stretch or writhing viscera motor reaction, with alternating pushups and abdominal extensions. This complex behavior involves different mediators in the development of inflammatory hyperalgesia, as the release of endogenous substances that excite nerve endings, prostaglandins $\left(\mathrm{PGE}_{2}\right.$ e $\left.\mathrm{PGF}_{2 \alpha}\right)$ and bradykinin derived macrophages and mast cells residing in the peritoneal. This test showed that all groups treated with LDH-Mef nanoparticles presented an analgesic effect greater than the non-intercalated MefH, which is clearly evident in the dose of LDH-Mef $200 \mathrm{mg} / \mathrm{kg}$. The analgesic response of the intercalated compound was enhanced when compared to the free compound at the $200 \mathrm{mg} / \mathrm{kg}$ dose level. Probably, the improved analgesic effect can be attributed to the increase in aqueous solubility and controlled release of Mef from LDH nanoparticles, as described by Rives' group [23,25,26].

\section{Conclusions}

A set of physicochemical techniques supported by Density Functional Theory calculations confirmed the immobilization of the mefenamic acid into the nanocarrier Layered Double Hydroxide in its anionic 
form. The anti-inflammatory activity, hemolytic and antinociceptive assays were used to evaluate the pharmacological effects of LDH-Mef (40 wt\% of drug). The higher tolerated hemolytic concentration for LDH-Mef (1.83 mM) compared to MefH $(0.48 \mathrm{mM})$ showed the improved hemolytic effect of the nanocarrier with Mef. Pretreatment of animals with LDH-Mef reduced carrageenan-, dextran sulfate- and $\mathrm{PGE}_{2}$-induced paw edema. LDH-Mef also decreases total leucocytes and neutrophil counts of the peritoneal cavity after inflammation induction with carrageenan. In nociception models, pretreatment with LDH-Mef reduced mechanical hypernociception carrageenan-induced after 3-4 h and also the number of writhings induced by acetic acid.

\section{Acknowledgments}

The authors are grateful to the Fundação de Amparo à Pesquisa do Estado de São Paulo (FAPESP), Conselho Nacional de Desenvolvimento Científico e Tecnológico (CNPq), and Nanobiomed (Nanomedicine Network/CAPES) for the financial support and scholarships. Vanessa Cunha is thankful for the PhD fellowship (Programa Institucional de Doutorado Sanduíche no Exterior) provided by the Coordenação de Aperfeiçoamento de Pessoal de Nível Superior (CAPES). We are also thankful to the Laboratório de Espectroscopia Molecular (LEM, Instituto de Química - USP) for the Raman spectra recording.

\section{Appendix A. Supplementary data}

Supplementary data to this article can be found online at http://dx. doi.org/10.1016/j.msec.2015.08.037.

\section{References}

[1] J.M. Oh, D.H. Park, S.J. Choi, J.H. Choy, LDH nanocontainers as bio-reservoirs and drug delivery carriers, Recent Pat. Nanotechnol. 6 (2012) 200-217.

[2] B. Saifullah, P. Arulselvan, M.E.E. Zowalaty, S. Fakurazi, T.J. Webster, B.M. Geilich, M.Z. Hussein, Development of a biocompatible nanodelivery system for tuberculosis drugs based on isoniazid-Mg/Al layered double hydroxide, Int. J. Nanomedicine 9 (2014) 4749-4762

[3] L. Qin, M. Wang, R. Zhu, S. You, P. Zhou, S. Wang, The in vitro sustained release profile and antitumor effect of etoposide-layered double hydroxide nanohybrids, Int. J Nanomedicine 8 (2013) 2053-2064

[4] J. Chakraborty, S. Roychowdhury, S. Sengupta, S. Ghosh, Mg-Al layered double hydroxide-methotrexate nanohybrid drug delivery system: evaluation of efficacy, Mater. Sci. Eng. C 33 (2013) 2168-2174.

[5] C.J. Serna, J.L. White, S.L. Hem, Structural survey of carbonate-containing antacids, J. Pharm. Sci. 67 (1978) 324-327.

[6] K.H. Holtermüller, M. Liszkay, I. Bernard, W. Haase, Talcivent study group: treatment for benign gastric ulcer with low-dose antacid versus ranitidine: results of a doubleblind, randomly allocated, multicentre trial, Eur. J. Gastroenterol. 5 (1993) 139-144.

[7] A. Tarnawski, K. Tanoue, T.G. Douglas, F.L. Irwin Jr., J.J. Sarfeh, Cellular mechanism involved in duodenal ulcer healing and the quality of mucosal scar. Effect of Talcid and Omeprazole treatment, Gastroenterology 108 (1995) A236.

[8] C. Forano, T. Hibino, F. Leroux, C. Taviot-Guého, Handbook of clay science, in: F. Bergaya, T. BKG, G. Lagaly (Eds.), Developments of clay science, 1, Elsevier, Amsterdam 2006, pp. 1021-1095.

[9] X.F. Wang, S.Q. Liu, S.P. Li, Methotrexatum intercalated layered double hydroxides: statistical design, mechanism explore and bioassay study, Mater. Sci. Eng. 49 (2015) 330-337.

[10] A.I. Khan, L.X. Lei, A.J. Norquist, D. O'Hare, Intercalation and controlled release of pharmaceutically active compounds from a layered double hydroxide, Chem. Comm. 22 (2001) 2342-2343.

[11] C.R. Gordijo, C.A.S. Barbosa, A.M.C. Ferreira, V.R.L. Constantino, D.O. Silva, Immobilization of ibuprofen and copper-ibuprofen drugs on layered double hydroxides, J. Pharm. Sci. 94 (2005) 1135-1148.

[12] K. Zhao, G. Rong, G. Guo, X. Luo, H. Kang, Y. Sun, C. Dai, X. Wang, X. Wang, Z. Jin, S. Cui, Q. Sun, Synthesis, characterization, and immune efficacy of layered double hydroxide@SiO $\mathrm{S}_{2}$ nanoparticles with shell-core structure as a delivery carrier for Newcastle disease virus DNA vaccine, Int. J. Nanomedicine 10 (2015) 2895-2911.

[13] D.Y. Tian, Z.L. Liu, S.P. Li, X.D. Li, Facile synthesis of methotrexate intercalated layered double hydroxides: particle control, structure and bioassay explore, Mater. Sci. Eng. C 45 (2014) 297-305.

[14] V.R.R. Cunha, J. Tronto, J.B. Valim, A.M.C. Ferreira, V.R.L. Constantino, Layered double hydroxide: inorganic nanoparticles for storage and release of species of biological and therapeutic interest, Quím. Nova 33 (2010) 159-171.

[15] J.H. Choy, J.S. Jung, J.M. Oh, M. Park, J. Jeong, Y.K. Kang, et al., Layered double hydroxide as an efficient drug reservoir for folate derivatives, Biomaterials 25 (2004) 3059-3064.
16] L. Tammaro, U. Costantino, A. Bolognese, G. Sammartino, G. Marenzi, A. Calignano, et al., Nanohybrids for controlled antibiotic release in topical applications, Int. J. Antimicrob. Agents 29 (2007) 417-423.

[17] J.H. Choy, S.Y. Kwak, J.S. Park, Y.J. Jeong, Cellular uptake behavior of [gamma-P-32] labeled ATP-LDH nanohybrids, J. Mater. Chem. 11 (2001) 1671-1674.

[18] J.M. Oh, S.J. Choi, G.E. Lee, J.E. Kim, J.H. Choy, Inorganic metal hydroxide nanoparticles for targeted cellular uptake through clathrin-mediated endocytosis, Chem. Asian. J. 4 (2009) 67-73.

[19] J. Chen, R. Shao, L. Li, Z.P. Xu, W. Gu, Effective inhibition of colon cancer cell growth with MgAl-layered double hydroxide (LDH) loaded 5-FU and PI3K/ mTOR dual inhibitor BEZ-235 through apoptotic pathways, Int. J. Nanomedicine 9 (2014) 3403-3411.

[20] S.J. Choi, J.M. Oh, J.H. Choy, Toxicological effects of inorganic nanoparticles on human lung cancer A549 cells, J. Inorg. Biochem. 103 (2009) 463-471.

[21] S.C. Smolinske, A.H. Hall, S.A. Vandenberg, D.G. Spoerke, P.V. McBride, Toxic effects of nonsteroidal anti-inflammatory drugs in overdose: an overview of recent evidence on clinical effects and dose response relationships, Drug Saf. 5 (1990) 252-274.

[22] O. Catanzano, S. Acierno, P. Russo, M. Cervasio, M.D.B. De Caro, A. Bolognese, G. Sammartino, L. Califano, G. Marenzi, A. Calignano, D. Acierno, F. Quaglia, Melt-spun bioactive sutures containing nanohybrids for local delivery of anti-inflammatory drugs, Mater. Sci. Eng. 43 (2014) 300-309.

[23] V. Rives, M. Del Arco, C. Martín, Layered double hydroxide as drug carriers and for controlled release of non-steroidal anti-inflammatory drugs (NSAIDs): a review, J. Control. Release 169 (2013) 28-39.

[24] S. Fiorucci, L. Santucci, E. Distrutti, NSAIDs, coxibs, CINOD and H2S-releasing NSAIDs: what lies beyond the horizon, Dig. Liver Dis. 12 (2007) 1043-1051.

[25] M. Del Arco, A. Fernández, C. Martín, M.L. Sayalero, V. Rives, Solubility and release of fenamates intercalated in layered double hydroxides, Clay Miner. 43 (2008) 255-265.

[26] M. Del Arco, A. Fernandez, C. Martin, V. Rives, Release studies of different NSAIDs encapsulated in Mg, Al, Fe-hydrotalcites, Appl. Clay Sci. 42 (2009) 538-544.

[27] V.R.R. Cunha, P.A.D. Petersen, M.B. Goncalves, H.M. Petrilli, C. Taviot-Gueho, F. Leroux, et al., Structural, spectroscopic (NMR, IR and Raman) and DFT investigation of the self-assembled nanostructure of pravastatin-LDH (layered double hydroxides) systems, Chem. Mater. 24 (2012) 1415-1425.

[28] C.A.S. Barbosa, A.M.C. Ferreira, A.C.V. Coelho, V.R.L. Constantino, Characterization of $\mathrm{Cu}(\mathrm{II})$ phthalocyanine tetrasulfonate intercalated and supported on layered double hydroxides, J. Incl. Phenom. Macrocycl. Chem. 42 (2002) 15-23.

[29] M.J. Frisch, G.W. Trucks, H.B. Schlegel, G.E. Scuseria, M.A. Robb, J.R. Cheeseman, et al., Gaussian 03, Revision C.02. 2003.

[30] M.P. Andersson, P. Uvdal, New scale factors for harmonic vibrational frequencies using the B3LYP density functional method with the triple- $\zeta$ basis set $6-311+$ G(d,p), J. Phys. Chem. A 109 (2005) 2937-2941.

[31] A.P. Scott, L. Radom, Harmonic vibrational frequencies: an evaluation of hartreefock, moller-plesset, quadratic configuration interaction, density functional theory, and semiempirical scale factors, J. Phys. Chem. 100 (1996) 16502-16513.

[32] L.S. Chaves, L.A.D. Nicolau, R.O. Silva, F.C. Barros, A.L. Freitas, K.S. Aragão, et al., Antiinflammatory and antinociceptive effects in mice of a sulfated polysaccharide fraction extracted from the marine red algae Gracilaria caudata, Immunopharmacol. Immunotoxicol. 35 (2013) 93-100.

[33] T.M. Cunha, W.A. Verri Jr., G.G. Vivancos, I.F. Moreira, S. Reis, C.A. Parada, et al., An electronic pressuremeter nociception paw test for mice, Braz. J. Med. Biol. Res. 37 (2004) 401-407.

[34] R. Koster, M. Anderson, E.J. Beer, Acetic acid for analgesic screening, Federation Proceeds. 18 (1959) 412-416.

[35] M. Del Arco, A. Fernández, C. Martín, V. Rives, Intercalation of mefenamic and meclofenamic acid anions in hydrotalcite-like matrixes, Appl. Clay Sci. 36 (2007) $133-140$.

[36] U. Costantino, N. Coletti, M. Nocchetti, G.G. Aloisi, F. Elisei, Anion exchange of methyl orange into $\mathrm{Zn}-\mathrm{Al}$ synthetic hydrotalcite and photophysical characterization of the intercalates obtained, Langmuir 15 (1999) 4454-4460.

[37] P. Atkins, T. Overton, J. Rourke, M. Weller, F. Armstrong, M. Hagerman, Shriver \& Atkins' Inorganic Chemistry, 5th Ed. W. H. Freeman and Company, New York, 201025 Part 1.

[38] L. Fang, S. Numajiri, D. Kobayashi, H. Ueda, K. Nakayama, H. Miyamae, Y. Morimoto, Physicochemical and crystallographic characterization of mefenamic acid complexes with alkanolamines, J. Pharm. Sci. 93 (2004) 144-154.

[39] V.R.R. Cunha, C.M.S. Izumi, P.A.D. Petersen, A. Magalhães, M.L.A. Temperini, H.M. Petrilli, V.R.L. Constantino, Mefenamic acid anti-inflammatory drug: probing its polymorphs by vibrational (IR and Raman) and solid-state NMR spectroscopies, J. Phys. Chem. B 118 (2014) 4333-4344.

[40] D.R. De Araujo, S.S. Tsuneda, C.M. Cereda, G.F. Del, F. Carvalho, O.S. Preté, et al., Development and pharmacological evaluation of ropivacaine-2-hydroxypropylbeta-cyclodextrin inclusion complex, Eur. J. Pharm. Sci. 33 (2008) 60-71.

[41] K. Seibert, Y. Zhang, K. Leahy, S. Hauser, J. Masferrer, W. Perkins, et al., Pharmacological and biochemical demonstration of the role of cyclooxygenase 2 in inflammation and pain, Proc. Natl. Acad. Sci. 91 (1994) 12013-12017.

[42] N.L. Quintão, R. Medeiros, A.R. Santos, M.M. Campos, J.B. Calixto, The effects of diacerhein on mechanical allodynia in inflammatory and neuropathic models of nociception in mice, Anesth. Analg. 6 (2005) 1763-1769.

[43] D.A. Rowley, E.P. Benditt, 5-hydroxytryptamine and histamine as mediators of the vascular injury produced by agents which damage mast cells in rats, J. Exp. Med. 103 (1956) 399-415.

[44] L.M. Solomon, L. Juhlin, M.B. Kirschenbaum, Prostaglandin on cutaneous vasculature, J. Invest. Dermatol. 51 (1968) 280-282 
[45] M. Hamza, Role of neutrophils in the anti-inflammatory and antinociceptive activity of the cyclooxygenase inhibitors indomethacin and nimesulide, J. Egypt Soc. Pharmacol. Exp. Ther. 29 (2008) 507-526.

[46] F.J.C. Alves, M.B.M. Tavares, F.C. Barja, C.F. Benjamim, F.A. Basile, S.M. Arraes, et al., Neutrophil function in severe sepsis, Endocr. Metab. Immune Disord. Drug Targets 2 (2006) 151-158.
[47] S.J. Klebanoff, Myeloperoxidase, Proc. Assoc. Am. Physicians 111 (1999) 383-389.

[48] T.M. Cunha, J.W.A. Verri, I.R. Schivo, M.H. Napimoga, C.A. Parada, S. Poole, et al., Crucia role of neutrophils in the development of mechanical inflammatory hypernociception, J. Leukoc. Biol. 83 (2008) 824-832. 